Faculdade

de Ciências Econômicas UFRGS

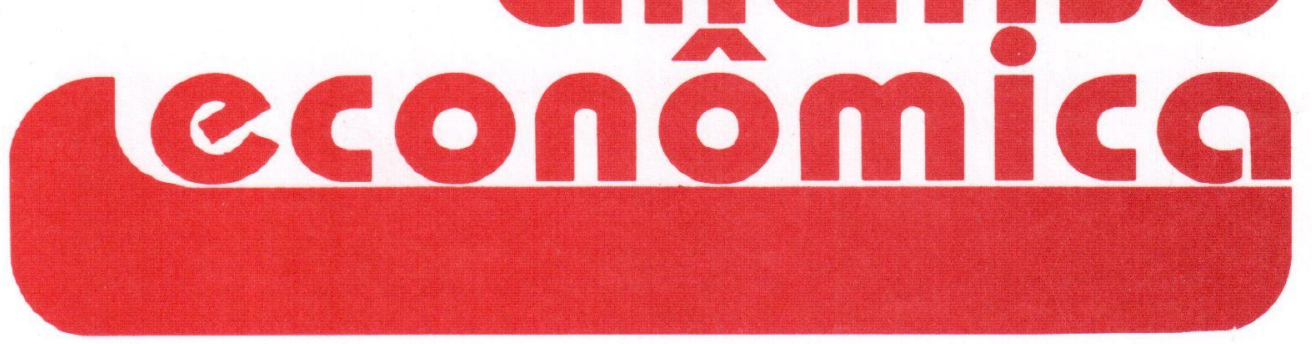

Balança Comercial e Capacidade

Produtiva da Indústria de Transformação

- Flávio Benevett Fligenspan

- Jeferson Luis Bittencourt

Breves Reflexões sobre a Relevância

da História da Teoria Econômica

- Gilberto Tadeu Lima

A Competitividade do Arroz Gaúcho

e seus Condicionantes

- Augusto M. Alvim

- Carlos G. A. Mielitz Netto

Uma Análise da Economia de Ricardo

- Liderau S. Marques Junior

A Estratégia de Substituição de

Importações Revisitada

- Alex Pereira Benício

- Joanílio Rodolpho Teixeira

The Refinements of the Orthodox Macroeconomic Theory and the Post Keynesian Theory

- Fernando Ferrari Filho

Instrumentos de Gestão Ambiental

- Jaildo Santos Pereira

- Vitor Emanuel Tavares

The Economic Implications for

Sustainable Mining

- Dina Franceschi

- James R. Kahn

Mudança Institucional e Estrutural na

Economia Brasileira do Início dos Anos Noventa

- Eduardo Simões de Almeida
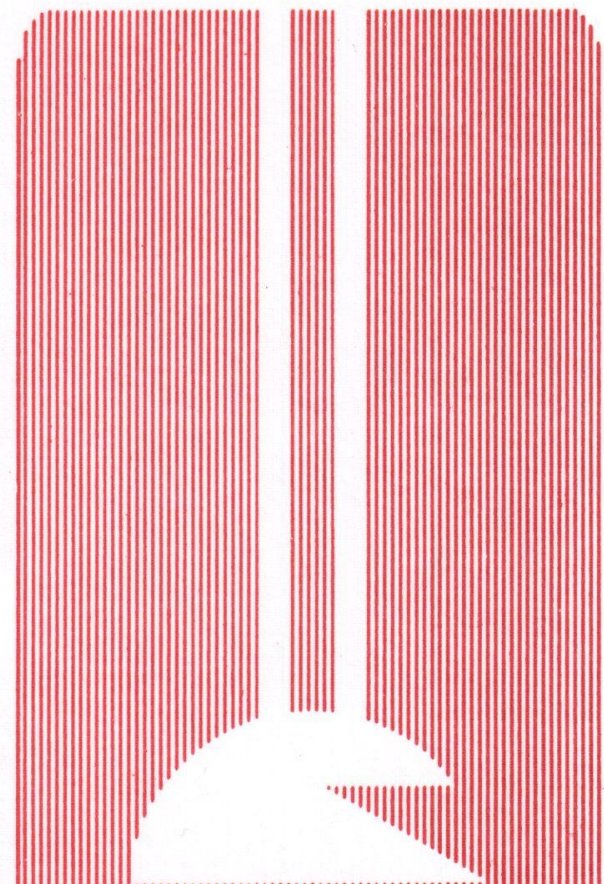

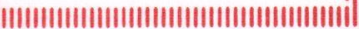
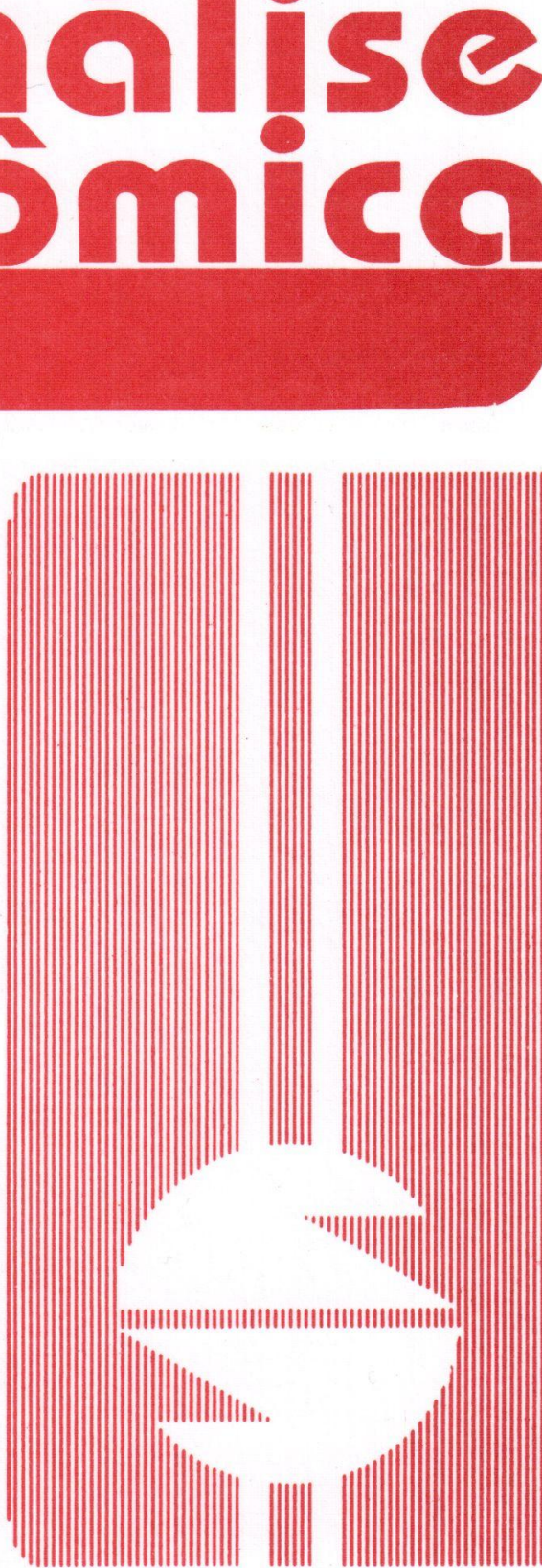
UNIVERSIDADE FEDERAL DO RIO GRANDE DO SUL

Reitora: Prof ${ }^{a}$. Wrana Maria Panizzi

FACULDADE DE CIÊNCIAS ECONÔMICAS

Diretora: Prof . Otilia Beatriz Kroeff Carrion

CENTRO DE ESTUDOS E PESQUISAS ECONÔMICAS

Diretor. Prof. Fernando Ferrari Filho

DEPARTAMENTO DE CIÊNCIAS ECONÔMICAS

Chefe: Prof. Luiz Alberto Oliveira Ribeiro de Miranda

CURSO DE PÓS-GRADUAÇÃO EM ECONOMIA

Coordenador. Prof. Marcelo Savino Portugal

CURSO DE PÓS-GRADUAÇÃO EM ECONOMIA RURAL

Coordenador. Prof. Carlos Guilherme A. Mielitz Netto

CONSELHO EDITORIAL: Achyles B. Costa, Aray M. Feldens, Carlos A. Crusius, Carlos G. A. Mielitz Netto, Eduardo A. Maldonado Filho, Eduardo P. Ribeiro, Eugênio Lagemann, Fernando Ferrari Filho, Gentil Corazza, Marcelo S. Portugal, Nali J. Souza, Otília B. K. Carrion, Paulo A. Spohr, Paulo D. Waquil, Pedro C. D. Fonseca, Roberto C. Moraes, Ronald Otto Hillbrecht, Stefano Florissi, Eleutério F. S. Prado (USP), Fernando H. Barbosa (FGV/RJ), Gustavo Franco (PUC/RJ), João R. Sanson (UFSC), Joaquim P. Andrade (UnB), Juan H. Moldau (USP), Paul Davidson (Univ. of Tennessee), Werner Baer (Univ. of lllinois).

COMISSÃO EDITORIAL: Eduardo Augusto Maldonado Filho, Fernando Ferrari Filho, Gentil Corazza, Marcelo Savino Portugal, Paulo Dabdab Waquil; Roberto Camps Moraes.

EDITOR: Gentil Corazza

EDITOR ADJUNTO: Pedro Silveira Bandeira

SECRETARIA: Fábio Sparremberger. Revisão de textos: Vanete Ricacheski.

FUNDADOR: Prof. Antônio Carlos Santos Rosa

Os materiais publicados na revista Análise Econômica são da exclusiva responsabilidade dos autores. É permitida a reprodução total ou parcial dos trabalhos, desde que seja citada a fonte. Aceita-se permuta com revistas congêneres. Aceitam-se, também, livros para divulgação, elaboração de resenhas e recensões. Toda correspondência, material para publicação (vide normas na terceira capa), assinaturas e permutas devem ser dirigidos ao seguinte destinatário:

PROF. GENTIL CORAZZA

Revista Análise Econômica - Av. João Pessoa, 52 CEP 90040-000 PORTO ALEGRE - RS, BRASIL 


\title{
EM ALGUM LUGAR DO \\ PASSADO: BREVES REFLEXÕES SOBRE A RELEVÂNCIA DA HISTÓRIA DA TEORIA ECONÔMICA ${ }^{1}$
}

\author{
Gilberto Tadeu Lima ${ }^{2}$
}

\begin{abstract}
The ideas of economists and political philosophers, both when they are right and when they are wrong, are more powerful than is commonly understood. Practical men, who believe themselves to be quite exempt from any intellectual influences, are usually the slaves of some defunct economist. Madmen in authority, who hear voices in the air, are distilling their frenzy from some academic scribber of a few years back.
\end{abstract}

John Maynard Keynes

\section{RESUMO}

O presente ensaio objetiva tecer algumas considerações um tanto quanto fragmentárias acerca do significado e da importância da história da teoria econômica para o progresso científico em teoria econômica. Para tanto, incorpora vários conceitos em nível de sociologia do conhecimento formulados por Pierre Bourdieu, em particular sua frutifera formulação sobre a dinâmica do complexo processo de competição que prevalece em um determinado campo científico. O ensaio argumenta que o campo científico habitado pelos economistas, campo social como outro qualquer, é palco de uma luta em que se disputa, entre outras coisas, o monopólio da definição legitima da real importância de análises centradas no passado da disciplina.

Cód. AEA: $030 \quad$ Palavras-chave: teoria econômica; história do pensamento econômico; conhecimento econômico; campo científico; sociologia do conhecimento.

\footnotetext{
${ }^{1}$ Concluída alguns anos atrás, a elaboração deste ensaio contou com os pertinentes comentários de Ricardo Tolipan, Vitória Saddi, José Márcio Rego e Paulo Arvate, cabendo, obviamente, as isenções de praxe. Alguns de seus elementos foram esparsamente incorporados à introduçao a Lima (1992). A tentação em alterá-lo para esta publicação, principalmente para incorporar vários desenvolvimentos recentes na sociologia do conhecimento cientifico, acabou cedendo à conclusão de que, afinal, sua mensagem básica é que a história importa. Sobre a relevância desses desenvolvimentos recentes para uma análise sociológica do discurso econômico, ver Lima (1994)

${ }^{2}$ Instituto de Economia da Universidade Estadual de Campinas (glima@eco.unicamp.br).
}

\begin{tabular}{|l|l|l|l|l|}
\hline Análise Econômica & ANO 17 & N. 31 & Março/99 & p. 30-44 \\
\hline
\end{tabular}




\section{ABSTRACT}

This essay is intended to put forward some fragmentary remarks about the meaning and importance of the history of economic theory to scientific progress in and of economic theory. To that end, it incorporates some sociological formulations developed by Pierre Bourdieu, particularly his interesting approach to the complex process of competition that prevails in a given scientific field. Such an incorporation is predicated upon the belief that the scientific field inhabited by economists, like any other scientific field, is itself a social locus of intense disputes over the actual importance of historical studies of the discipline.

AEA Code: 030

Key words: economic theory; history of economic thought; economic knowledge; scientific field; sociology of knowledge.

\section{1 - INTRODUÇÃO}

Este ensaio tem por objetivo tecer considerações um tanto quanto fragmentárias acerca do significado e das virtualidades da história da teoria econômica para a dinâmica do progresso científico em teoria econômica propriamente dita. Longe de almejar esgotar tão complexa e, por conseguinte, polêmica questão, o ensaio pretende apenas incorporar ao recorrente debate sobre a real importância da história da teoria econômica alguns elementos certamente merecedores de consideração, em particular alguns importados da sociologia do conhecimento cientifico, os quais, entretanto, têm sido menosprezados por grande parte dos economistas. Dado o caráter altamente controverso dos debates em torno da utilidade efetiva dos programas de pesquisa centrados na análise dos conteúdos das formulações que habitam (cronologicamente) o passado, não nos causará estranheza, portanto, se as reflexões a seguir forem consideradas, emprestando o sugestivo título de Rubem Fonseca, Vastas emoções e pensamentos imperfeitos.

\section{2 - A HISTÓRIA DA TEORIA ECONÔMICA COMO CONTROVÉRSIA}

A história das idéias econômicas configura um campo do conhecimento científico onde polêmicas e controvérsias constituem a própria atividade normal (no sentido Kuhniano) desenvolvida pelos teóricos que a elas se dedicam. Como a economia é uma ciência essencialmente social e, assim, marcadamente influenciada pela weltanschauungen de seus praticantes, a existência de múltiplas interpretações acerca de um mesmo objeto analítico é uma indicação de robustez, vigor e dinamismo, e não de fraqueza, debilidade ou impotência dessa ciência, contribuindo, de forma significativa, para o progresso da e na própria teoria econômica. Ser valoricamente condicionada não é um atributo apenas da metafísica, o mesmo ocorrendo com a própria ciência (Horkheimer, 1968). 
Portanto, a investigação científica não configura um processo meramente lógico, sendo, inclusive, socialmente determinada. A própria dinâmica do conhecimento científico não pode ser apreendida, por conseguinte, quando fatores sociológicos, psicológicos e antropológicos estão ausentes do esforço interpretativo em curso, já que todo conhecimento tem seus mom vimentos orientados, dirigidos e comandados por interesses dos mais variados (Habermas, 1987). Enquanto atores do processo de conhecimento, os cientistas não pautam seu comportamento intelectual apenas pelo dictum ciência pela ciência, sendo eles, em verdade, impulsionados por um conjunto mais amplo e variado de objetivos. Mesmo o iniciante no campo científico escolhido, não está meramente produzindo conhecimento, mas sobretudo investindo num tipo de capital social que supõe lhe garantirá uma posição de destaque entre os profissionais desse campo. Ademais, o próprio processo de adesão a um determinado grupo de idéias econômicas, por parte da comunidade acadêmica, segue uma lógica que extrapola os limites da órbita estritamente científica:

The main point is that ideas find academic acceptance not necessarily because of their intrinsic scientific worth - for there is no unambiguous way of specifying what this means in a world of partial knowledge - but rather because they are salable as tools which enable their users more easily to reach their goals (Earl, 1983, p.90)

Assim, o próprio termo comportamento intelectual é bastante restritivo, não dando conta do aspecto multidimensional da atividade científica. Por ter sua visão lógico-analítica dos fenômenos em jogo condicionada por variados elementos valóricos, o investigador forçosamente dota suas concepções econômicas de um caráter não-neutro. No entanto, convém salientar de antemão que o fato de reconhecermos tal condicionamento social do processo de conhecimento não conduz obrigatoriamente ao relativismo epistemológico, a menos que o ideal onírico da verdade absoluta seja o parâmetro de medida empregado. A sociolologia do conhecimento é, portanto, o framework mais apropriado para aqueles que pretendem apreender, ao menos em seus delineamentos gerais, o processo de geração e acumulação de conhecimento científico em economia. ${ }^{3}$ Ao contrário do suposto pela vertente positivista (Leopold Von Ranke, por exemplo, com seu famoso aforisma wie es eigentlich gewesen, ou seja, a história deve mostrar o passado apenas como ele realmente se passou), o conhecimento histórico não configura um reflexo exato, porquanto isento de quaisquer fatores subjetivos, dos fenômenos situados no passado. Apesar de ser comum o dito se-

3 Igualmente colocando a problemática do conhecimento nessa mais ampla e frutífera perspectiva analítica, José Márcio Rego (Anpec, 1989) realiza uma interessante análise Kuhniana de vários desenvolvimentos recentes na área de retórica da economia. Para uma clássica análise Kuhniana da importância atribuída à história do pensamento econômico pelo chamado mainstream da profissão, ver Ward (1975) 
gundo o qual os fatos falam por si mesmos, a verdade é que eles se expressam somente quando são abordados pelo historiador: é sua atribuição definir quais os fatos que encenarão a história e em qual ordem e contexto.

No processo de conhecimento, especialmente em ciências humanas, sujeito e objeto constituem uma totalidade orgânica e, ao guardarem entre si uma relação de estreita interdependência, o convertem, como bem observou Karl Mannheim, em algo socialmente condicionado. ${ }^{4}$ Assim, é inevitável o condicionamento social do processo de conhecimento histórico, fato do qual, regra geral, grande parte dos cientistas parece não ter consciência, enganando-se a ponto de considerar suas atitudes como pura e candidamente científicas, vale dizer, condicionadas única e tão-somente por fatores de natureza estritamente científica. No entanto, convém frisar que a conversão de tal conjunto de fatores extra-e meta-econômicos numa espécie de deus ex-machina que acaba por relativizar por completo o debate científico em economia é igualmente desvirtuante. Deificá-los ou exorcizá-los são polarizações que compartilham do mesmo gênero de reducionismo ingênuo: no primeiro caso, nos aproximamos perigosamente da metafísica, diminuindo, conseqüentemente, o grau de cientificidade; no segundo, nos municiamos de uma neutralidade absolutamente incompatível com a natureza do objeto em questão.

Essa multiplicidade interpretativa inerente, traço que ao mesmo tempo incita e modela a evolução da teoria econômica, mas não nega seu caráter científico, somente poderá ter suas virtudes apreendidas e exploradas produtivamente caso se reconheça que as ciências alimentam-se não apenas de vigorosos debates, mas, acima de tudo, da oposição mais radical entre os vários paradigmas que sustentam as diferentes vertentes teóricas. À semelhança do que ocorre numa sociedade totalitária, um determinado campo científico tenderá a involuir sempre que o debate, o questionamento e a diversidade deixarem de fazer parte do ritmo cotidiano dos acontecimentos. Como observou o filósofo da ciência I. Lakatos, a coexistência competitiva de variados paradigmas não configura uma anomalia, mas, ao contrário, algo que ativa o padrão normal do progresso científico. Essa virtualidade da competição paradigmática, onde o pluralismo teórico é preferível ao monismo teórico, foi assim registrada por ele:

The history of science has been and should be a history of competing research programmes (or, if you wish, 'paradigms') but it has not been and must not become a suc-

\footnotetext{
${ }^{4}$ Crítico da teoria do conhecimento que persegue o ideal da verdade absoluta, Mannheim procurou destacar o papel dos fatores sociais nas atitudes e opiniões dos cientistas. A seu ver, existe uma relação estreita entre as concepções dos homens - concebidos como seres sociais, e não como meros indivíduos - sobre os problemas sociais e as condições sociais que the são próprias (cf. Mannheim, 1968).
} 
cession of periods of normal science: the sooner competition starts, the better for progress (Lakatos, 1970, p.155).

\section{3 - FUNCIONALIDADE DA HISTÓRIA DA TEORIA ECONÔMICA}

O campo científico é o locus de uma luta concorrencial entre seus participantes, e não uma paisagem imaculada marcada por uma relação exclusivamente cooperativa entre eles tendo em vista tão-somente o avanço científico. Campo social como outro qualquer, também ele configura um permanente espaço de disputa do poder e da autoridade. Como registrou Pierre Bourdieu, "o universo 'puro' da mais 'pura' ciência é um campo social como outro qualquer, com suas relações de força e monopólios, suas lutas e estratégias, seus interesses e lucros, mas onde todas essas invariantes revestem formas específicas" (Bourdieu, 1983a, p.122). Locus de uma acirrada disputa concorrencial, o campo científico é um espaço onde os oponentes freqüentemente engalfinham-se em nome de um conjunto amplo de interesses extracientíficos, não se limitando a buscar meramente contribuir para o avanço da ciência. Segundo Bourdieu:

O que está em jogo especificamente nessa luta é o monopólio da autoridade cientifica definida, de maneira inseparável, como capacidade técnica e poder social; ou, se quisermos, o monopólio da competência científica, compreendida enquanto capacidade de falar e de agir legitimamente (isto é, de maneira autorizada e com autoridade), que é socialmente outorgada a um agente determinado (Bourdieu, 1983a, p.122-3).

Assim, equivocam-se aqueles que buscam dissociar aquilo que na competência científica seria pura representação social, de um lado, e o que seria pura competência técnica, de outro lado. Enquanto arena de disputa política pela dominação científica, o campo científico não terá sua lógica comportamental apreendida caso desconsideremos que o interesse por uma certa atividade de natureza cientifica tem sempre uma dupla face: uma intrinseca (importância pessoal) e uma extrínseca (importância para os pares). Em outras palavras, o trabalho de um cientista não deve ser interessante apenas para ele, mas deve ser igualmente importante para.os demais membros da comunidade. Enquanto locus de poder como outro qualquer (especificidades à parte), o colégio invisível dos economistas também demanda de seus membros, por conseguinte, a capacidade de conceber e implementar uma série de estratégias de consagração e legitimação, entendidas estas como mecanismos amplos e variados de conquista de reconhecimento acadêmico. Nessa empreitada, as formas exclusivamente técnicas de consagração são condições necessárias nem sempre suficientes. Como retomamos em seguida, com base nas formulações em nivel de sociologia do conhecimento desenvolvidas por Pierre Bourdieu, a depreciação da história da teoria econômica por grande parte da visão convencional (fração dominante, em termos da distribuição do capital social acumulado, do cam- 
po científico em economia que procura desenvolver mecanismos de preservação de seu estatuto de dominação) e a conseqüente supervalorização das temáticas tidas como de fronteira contidas nos manuais científicos mais recentes, faz parte de uma estratégia de consagração e distinção simbólicas baseada numa particular configuração dos limites da atividade científica tida como verdadeiramente legitima.

Devemos ter em mente que as idéias que pisam à cena dessas divergências permanentes não brotam do nada (bootstraps theory), não resultando, muito menos, da operação automática de algum tipo de invisible hand, auctioneer, helicopter drop ou processo de tâtonnement, emprestando alguns dos artifícios analíticos recorrentemente utilizados, noutros contextos, pela visão convencional do mainstream. Emprestando uma pertinente observação de Ignácio Rangel, em economia, à semelhança do que ocorre na natureza, exnihilo, nihil: do nada nada se tira. Apesar de filhas de seu tempo, do qual herdam marcas profundas, uma exegese dessas idéias certamente nos levará para além das fronteiras estreitas do presente, tornando falso imaginar que uma recuperação das temáticas passadas seja uma contribuição importante para a história da teoria econômica, mas, por outro lado, não para o avanço da própria teoria econômica. Alguns elementos justificadores da necessidade de reconstituirmos um passado aparentemente soterrado por várias camadas de história podem ser buscados no historiador das mentalidades Robert Darnton:

\begin{abstract}
reconstituir mundos é uma das tarefas essenciais do historiador, e ele não a empreende pelo estranho impulso de escarafunchar arquivos e farejar papel embolorado mas para conversar com os mortos ...Se rompermos todo contato com mundos perdidos, estaremos condenados a um presente bidimensional e limitado pelo tempo; achataremos nosso próprio mundo (Darnton, 1987, p.7).
\end{abstract}

Já para os guardiões da fronteira oficial da ciência econômica - seletos magos da modernidade dotados de uma concepção hard science da teoria econômica ${ }^{5}$ - esse retorno ao passado não passa de um exercício extemporâneo e autotélico, devendo ser reservado ao deleite arqueológico dos historiadores da teoria econômica. Seguindo fielmente os passos de Descartes, simplesmente expulsam a história do corpo de conhecimento econômico propriamente dito. Seguem comportadamente o dito do mestre: imaginam que quando somos excessivamente curiosos acerca daquilo que ocorreu no passado, acabamos nos tornando ignorantes em relação ao presente (Descartes, 1981). No entanto, alargar o foco analítico no sentido de colocar

\footnotetext{
${ }^{5}$ Segundo Arida (1984), os modelos soft science (valorização da história do pensamento econômico) e hard science (sacralização da noção de fronteira do conhecimento), ao espelharem concepções distintas sobre a evolução da teoria econômica, caracterizam posições polares quanto ao significado de estudos na área de história do pensamento econômico.
} 
um conjunto de idéias econômicas numa perspectiva histórica mais ampla é fundamental para o entendimento e a compreensão de sua própria essência. Sendo o conhecimento econômico um processo (e não um estoque de dotações iniciais dadas), os elos da corrente histórica guardam entre si uma relação de estreita interdependência lógica. Como nos alerta o físico e filósofo da ciência David Bohm,

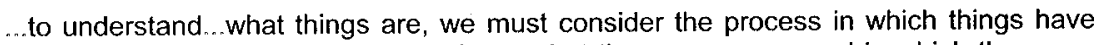
become, what they are starting out from, what they once were, and in which they continue to change and to become something else again in the future. (Georgescu-Roegen, 1988, p.313).

Assim, é fundamental que avaliemos a pertinácia dessa experiência recuperatória adotando a concepção soft science do saber econômico, reconhecendo a necessidade de i) um trabalho sério e atento de resgate dos antecedentes das idéias, ii) estabelecer seu eixo condutor e nexos causais e iii) delimitar suas conexões, paralelismos e diferenças em relação às versões alternativas - inexistentes apenas para os dogmáticos - do objeto analítico em questão. Contudo, é igualmente fundamental que dimensionemos corretamente as virtualidades dessa expedição ao passado, não esperando lá encontrar fórmulas acabadas aplicáveis integralmente à transformação da realidade presente. Essa ambição universalista, expressa na suposição de que a história é capaz de oferecer formulações teórico-práticas imutáveis, acaba por negar, além de desconsiderar as características elementares da dinâmica do processo histórico, a validade da própria investigação histórica. Admitida essa imutabilidade, uma única viagem ao momento $t-1$ (por que ir mais longe?) nos habilitaria a domar o presente e o futuro, convertendo as virtualidades da pesquisa histórica em algo do tipo once for all.

Em verdade, contudo, o parâmetro mais apropriado para aferir-se a aplicabilidade de um certo conjunto de idéias econômicas é enquadrá-las em seu contexto histórico original. Sendo elas produtos de seu tempo, o necessário exercício de recuperação de seus antecedentes históricos não deve pautar-se pela expectativa de que será possível aplicar um mesmo constructo teórico a formações econômico-político-sociais situadas em momentos diferentes do tempo cronológico. Caso queiramos nos reportar ao passado tendo em vista atuar sobre a realidade presente, é fundamental que o encaremos apenas como uma fonte de subsídios, e não como um antecipação fiel daquilo que será o devir.

Essa telescopagem do passado, admitida a natureza inerentemente competitiva da dinâmica do conhecimento científico, não deve ser encarada como uma busca desenfreada de uma síntese qualquer, mas, ao contrário, como uma tentativa de resgate e/ou preservação da própria identidade das idéias econômicas. Por não decretar a morte do passado, mas, pelo contrário, por configurar um produto histórico resultante da metamorfose deste, 0 
presente dele herda sua própria identidade. O presente e o futuro nada mais são do que o passado transmogrificado. O passado não é algo morto, mas algo que ainda sobrevive no presente e no futuro. Apesar de distinguíveis no tempo cronológico, passado, presente e futuro confundem-se no tempo lógico. Assim, por exemplo, a compreensão das características da fase superior do desenvolvimento de um fragmento qualquer da realidade, expressa na formulação teórica correspondente, nos habilita a avaliar corretamente seus antecedentes históricos. Como corolário, convém mencionar a apropriada observação de Marx quanto ao potencial das categorias que nos permitem compreender a estrutura da organização histórica da produção prevalecente na sociedade burguesa para a compreensão simultânea da estrutura das formações sócio-econômicas desaparecidas, obser.vação esta que o levou a derivar um de seus famosos aforismas:

A anatomia do homem é a chave da anatomia do macaco. O que nas espécies animais inferiores indica uma forma superior não pode, ao contrário, ser compreendido senão quando se conhece a forma superior (Marx, 1982, p.17).

Isso não implica, todavia, admitir, incorrendo novamente no equívoco de adotar a abordagem hard science, a necessária superioridade teórica das idéias presentes em relação às passadas, ou seja, o formàto por elas assumido no presente não necessariamente expressa o degrau mais alto, em termos de rigor analítico, consistência lógica e poder explicativo, até então alcançado. O tradicional rótulo de modernidade (The most up-dated contribution to ...) nem sempre recobre uma contribuição verdadeiramente merecedora do status que normalmente the é conferido pelos economistas de "fronteira", a menos que atribuamos a este termo uma conotação estritamente cronológica.

Ao postular a supremacia do conhecimento recentemente conquistado, a retórica triunfalista daqueles que fazem uma apreciação hard science da importância da história do pensamento econômico acaba por converter a economia numa ciência sem passado, ou, o que em essência é igualmente depreciativo, consideram que seu passado encerra nada mais que um estoque de erros, parte deles já superados pelos avanços recentes, e o restante a ser no futuro. Sendo assim, a assunção de uma nova formulação teórica necessariamente tornaria as anteriormente hegemônicas obsoletas ou meras peças de antiquário, uma vez que essa nova formulação já incorpora todo o possível potencial evolucionário dos clássicos do passado. O mais recente manual científico - e os "novos" mandamentos e preceitos nele contidos - parece ser aguardado por uma parcela considerável da comunidade com a mesma expectativa que povoa a mente daqueles que procuram a terra prometida. A cada "novo" manual científico colocado à disposição (o por ora mais recente macromanual de O. Blanchard e S. Fischer, 1989, por exemplo), os comportados fiéis do colégio invisível dos economistas reno- 
vam suas esperanças de ali encontrar a pedra filosofal que lhes permita decifrar os enigmas do universo econômico.

Caso abandonemos essa concepção hard science da dinâmica do progresso científico, claramente perceberemos que, apesar de mover-se também ao longo do tempo histórico - e não apenas do tempo lógico - a teoria econômica nem sempre o faz de maneira evolutiva, sendo vários os exemplos históricos de estagnação ou mesmo involução, como há tempos vem denunciando uma série de correntes rotuladas de radicais e heréticas (póskeynesianos, neo-ricardianos, neomarxistas, inter alia). Por esta razão, equivocam-se aqueles que insistem em subvalorizar, implicita ou explicitamente, a história das idéias econômicas, confinando-a aos limites estreitos da erudição inútil. A rígida distinção daí derivada, qual seja, entre o economista-historiador (erudito, mas um impotente em relação à "modernidade" cios problemas concretos), de um lado, e o economista-profissional (este sim, o detentor do saber objetivo e efetivo), de outro lado, em verdade enfraquece, mesmo quando apresenta-se com o discurso da necessária divisão intelectual do trabalho, a natureza e a validade da própria ciência econômica. Igualmente sectário e dogmático seria, contudo, invocar a tese de que a teoria econômica pode prescindir de uma determinada dimensão pragmática.

Por não estarem sujeitas a um esquema essencialmente positivista de superação, as inescapáveis controvérsias econômicas são mais uma ilustração da tradicional dicotomia entre as ciências da natureza e as ciências do espirito. Salvo para algumas vertentes teóricas postulantes de uma iden" tidade epistemológica entre a ciência econômica e as ciências naturais, o pluralismo paradigmático que engendra - e é engendrado por - essa competição permanente não é algo comprometedor do virtuosismo científico tão almejado pelos economistas, mas, muito ao contrário, constitui-se num ingrediente essencial para o fortalecimento da dinâmica do progresso teórico em economia. Seria um autoritarismo intelectual enorme desvalorizar tal multiplicidade com o argumento de que esta polui o esforço analítico com alguma variedade de relativismo epistemológico nefasto. Essa funcionalidade da diversidade paradigmática, ao emergir justamente de um ambiente intelectual aparentemente caótico, caracteriza um paradoxo apenas para os que insistem em conceber a teoria econômica como (mais) uma área do conhecimento humano onde a unicidade, a consensualidade e a universalidade podem e devem ser alcançadas através da utilização de mecanismos positivos de validação e refutação, consagração e decapitação. Ao procurar demonstrar que o investimento é trágico porquanto útil, Kalecki correta. mente nos lembrou que em várias circunstâncias o próprio objeto analítico em questão, e não sua representação teórica, é algo paradoxal. Ou ainda como sentenciou Marx, a verdade científica é sempre um paradoxo, se jul- 
gada pelo senso comum engendrado pela experiência cotidiana, já que esta apreende somente a aparência efêmera das coisas.

Conseqüentemente, é imperioso ressaltar a necessidade de revisitar periodicamente o passado, mesmo, talvez principalmente, quando objetivamos compreender as formulações teóricas mais recentes. No entanto, esta não é uma apreciação compartilhada pela visão convencional, presa que esta se encontra à concepção de que os mais recentes manuais científicos já incorporam aquilo que de importante foi teorizado até então. Para ela, a competição no "mercado" intelectual parece não ser um mecanismo tão virtuoso como supõem ser no de bens e serviços: a "mercadoria" conhecimento científico é tida como demasiado específica. Dada essa especificidade, o monopólio do conhecimento parece ser uma condição fundamental para que a cientificidade da economia não seja comprometida. Como observou Ricardo Tolipan, a validade de tal retorno ao passado, não o concebendo como mero arquivo morto, é recorrentemente questionada:

O estudo da história de uma ciência è desta, talvez, a única disciplina que enfrenta permanentemente o problema epistemológico de sua necessidade; se não se exprime diretamente como critica à existência desta disciplina, aparece na forma de uma mávontade difusa com relação a seu estudo e na dogmatização da noção de passado teórico que compõe seu programa oficial (Tolipan, 1989, p.13).

Além de ser um mero apêndice nos currículos tradicionais de economia, a disciplina de história do pensamento econômico em geral conta, o que não deveria surpreender, a história dos vencidos. Como toda e qualquer construção histórica é inexoravelmente seletiva, também aqui, à semelhança do que ocorre na delimitação das temáticas de fronteira, a história oficial é contada com o intuito whiggish de legitimar o presente como ápice do progresso científico até então conquistado, construindo seu passado como uma série contínua de contribuições resultando no "avançado" estado contemporâneo da disciplina. Sujeitos a várias restrições, os economistas maximizaram, naquele momento, a "função" conhecimento. Sendo racionais, os participantes da academia não hesitarão em considerar o passado como uma etapa meramente intermediária do desenvolvimento científico em economia que foi superada pelos gênios da criação. Olhar o passado converte-se, nesse modelo, num passatempo no qual obtemos uma quantidade insignificante de utiles. Ou, na melhor das hipóteses, o passado é incorporado como um tipo de bem cujo consumo gerará um nivel de utilidade típico de uma curva de indiferença situada muitíssimo próxima da origem.

\section{4 - SOCIOLOGIA DO CONHECIMENTO ECONÔMICO}

A real importância do passado de uma ciência humana é uma questão recorrente na agenda de lutas científicas travadas no presente pelos agentes que participam do campo cientifico em questão. No campo científico 
habitado pelos economistas - seres sociais dotados de um capital intelectual específico que pautam sua atuação pelo empenho em valorizá-lo - desenvolve-se um processo permanente de lutas onde disputa-se, entre outras coisas, o monopólio da imposição da definição legítima e autorizada do que seja realmente merecedor de atenção científica por parte da comunidade. Assim, a subvalorização de um retorno ao passado é parte integrante de uma estratégia mais ampla de disputa pelo monopólio da autoridade científica. Para entendermos a lógica do funcionamento do campo científico em economia, em particular a atitude depreciativa por parte dos adeptos da concepção hard science ém relação à história do pensamento econômico, é fundamental que incorporemos, portanto, uma série de elementos da sociologia do conhecimento, em particular alguns formulados por Pierre Bourdieu. Seu framework filosófico-sociológico, ao revelar coisas ocultas e muitas vezes reprimidas, criando problemas e gerando constrangimentos para as várias ciências, exorciza a filosofia idealista da ciência. Esta; ao postular que a ciência desenvolve-se de acordo com sua lógica imanente, ou, em outras palavras, que os cientistas (econômicos inclusive) são dotados de uma concepção imaculada, neutra do ponto de vista valórico, de sua atividade, acaba por descrever, de maneira equivocada, o campo científico à la T. More, T. Campanela, C. Fourier ou R. Owen. Bourdieu, ao contrário, empenha-se em mostrar que:

...o mundo científico é o palco de uma concorrência que, orientada para a busca de lucros específicos (prêmios, o Nobel e outros, prioridade da descoberta, prestígio, etc.) e assumida em nome de interesses específicos (isto é, irredutiveis aos interesses econômicos em sua forma comum e por isso percebidos como "desinteressados"), coloca em questão uma hagiografia científica da qual freqûentemente participam os cientistas e da qual eles necessitam para acreditar no que fazem (Bourdieu, 1983b, p. 17)

Assim, enganam-se aqueles que, escorados numa visão purista do processo científico, imaginam que o campo científico, enquanto arena de lutas políticas pela dominação científica, não tem sua lógica condicionada por diversos fatores de natureza exógena, respondendo unicamente a um conjunto de fatores engendrados por ela própria. Segundo Bourdieu:

Uma autêntica ciência da ciência só pode constituir-se com a condição de recusar radicalmente a oposição abstrata....entre uma análise imanente ou interna, que caberia mais propriamente à epistemologia e que restituiria a lógica segundo a qual a ciência engendra seus próprios problemas e, uma análise externa, que relacionaria esses problemas às condições sociais de seu aparecimento (Bourdieu, 1983a, p. 126).

Assim, Bourdieu sustenta que uma autêntica ciência da ciência deve fundar-se na pressuposição de que a atividade científica não é algo autônomo em relação ao contexto maior no qual ela encontra-se inserida. Em especial, é fundamental que tenhamos em mente que tal contexto - o campo científico no sentido amplo - se caracteriza por uma luta desenfreada pela dominação científica. Assim se expressa ele: 
É o campo científico, enquanto lugar de luta política pela dominação científica, que designa a cada pesquisador, em função da posição que ele ocupa, seus problemas, indissociavelmente politicos e científicos, e seus métodos, estratégias científicas que, pelo fato de se definirem expressa ou objetivamente pela referência ao sistema de posições políticas e científicas constitutivas do campo científico, são ao mesmo tempo estratégias politicas. Não há 'escolha' científica que não seja uma estratégia política de investimento objetivamente orientada para a maximização do lucro propriamente cientifico, isto é, a obtenção do reconhecimento dos pares-concorrentes (Bourdieu, 1983a, p. 126-7).

Enquanto espaço de manifestação de relações de poder, no qual as posições relativas dos agentes sociais envolvidos encontram-se definidas de antemão, o campo científico é uma arena de lutas em que está em disputa o monopólio da violência legítima (autoridade científica), luta travada entre aqueles que pretendem conservar a estrutura da distribuição do capital específico, de um lado, e aqueles que buscam subverter tal estrutura, de outro lado. Entre outras coisas, o campo científico pode ser definido, portanto, por meio da caracterização dos pivôs da disputa e dos interesses específicos em questão. Assim se manifesta Bourdieu:

A estrutura do campo é um estado da relação de força entre os agentes ou as instituições engajadas na luta ou, se preferirmos, da distribuição do capital específico que, acumulado no curso das lutas anteriores, orienta as estratégias ulteriores (Bourdieu, 1983b, p.90).

A luta pela autoridade cientifica coloca frente a frente dois grandes grupos de agentes, ambos com interesses, estratégias e práticas bastante diferenciadas. De um lado, se alinham aqueles que, sendo detentores de um elevado capital social, orientam sua atuação como investidores científicos com o intuito não apenas de maximizar os lucros simbólicos (reputação, prestigio, veneração por parte dos novatos, elogios em instâncias variadas de consagração como congressos, reuniões anuais, etc.) franqueados pela posição ocupada, mas, inclusive, com o firme e decidido propósito de manter a mesma. De outro lado, se agrupam aqueles que, estando numa situação desfavorável dentro do establishment, canalizam suas forças para a subversão da ordem estabelecida. Em termos do recorrente debate em torno da importância da história do pensamento econômico, sustentamos que, novamente emprestando a taxonomia proposta por Pérsio Arida, esses grupos empregam, respectivamente, os modelos hard science e soft science. A desqualificação ou, quando muito, a subvalorização dessa disciplina faz parte de uma estratégia de consagração e conservação fundada na delimitação rígida dos limites espaço-temporais da produção científica verdadeiramente importante. Com isso, somente os economistas familiarizados com a fronteira (oficial, diga-se de passagem) podem pronunciar-se com relação ao que efetivamente deve ser considerado digno do rótulo de cientifico. Ao fossilizarem o passado da ciência econômica, entronizarem sua fronteira espaço-temporal (vale novamente a ressalva acima) e se autopro- 
clamarem como os únicos capazes de promover o progresso da teoria econômica, os adeptos da concepção hard science que dominam o colégio invisível dos economistas exercem um poder de violência simbólica. Este poder, ao permitir a imposição legítima de significações e qualificações aos diversos conteúdos da economia, igualmente permite inculcar nos novatos um arbitrário cultural que nega qualquer sentido à história do pensamento econômico, viabilizando, desse modo, a reprodução dinâmica do status quo prevalecente.

Não surpreende, portanto, que as estratégias de subversão empreendidas pelos dominados sejam vistas como heréticas pelos dominantes. Assim, a própria definição dos objetos de disputa na luta científica é parte integrante da própria luta científica. Ao conseguirem impor sua concepção hard science, os dominantes acabam por impor uma definição de ciência de acordo com a qual a virtude consiste em ter, ser e fazer aquilo que eles têm, são e fazem. Aqueles que insistem em adotar um comportamento alternativo - os que possuem uma visão soft science, por exemplo - ficam condenados a um escárnio nem sempre velado, sofrendo, via de regra, formas variadas de exclusão acadêmica ${ }^{6}$. Coloca Bourdieu:

Na luta em que cada um dos agentes deve engajar-se para impor o valor de seus produtos e de sua própria autoridade de produtor legitimo, está sempre em jogo o poder de impor uma definição da ciência que mais esteja de acordo com seus interesses específicos. A definição mais apropriada será a que the permita ocupar legitimamente a posição dominante e a que assegure, aos talentos científicos de que ele é detentor a titulo pessoal ou institucional, a mais alta posição na hierarquia dos valores científicos... Existe assim, a cada momento, uma hierarquia social dos campos científicos - as disciplinas - que orienta fortemente as práticas e, particularmente, as 'escolhas' de 'vocação'. No interior de cada um deles há uma hierarquia social dos objetos e dos métodos de tratamento (Bourdieu, 1983a, p. 127-8).

\section{4 - CONSIDERAÇÕES FINAIS}

Ao reservarem para si próprios espaços especificos e cativos de consagração - incorporando, por exemplo, instrumentais matemáticos cada vez mais sofisticados - os idolatras da fronteira acabam por privar a economia dos aspectos historicistas necessários à sua caracterização como ciência. Conceber o tempo enquanto peça lógica e a-histórica do conhecimento econômico no contexto da batalha travada no campo científico dos economistas para legitimar a economia como ciência neutra, ou seja, autônoma e isenta de resquícios do passado, é a estratégia utilizada pelos adeptos da

${ }^{6}$ Como bem ouservou Eichner, "Economics can be viewed as a social system in which a small number of economists, because of the positions they occupy at the half dozen or so leading universities, exercise a disproportionate influence through the control they have over appointments, research funds, and access to journal" (cf. Eichner, A., 1983, P. 516). 
visão hard science para legitimar o signo fronteira do conhecimento e, simultaneamente, preservar sua posição enquanto fração hegemônica no metiér acadêmico. No entanto, apesar de auferirem vultuosos lucros simbólicos com essa estratégia, infelizmente condenam a ciência econômica a uma vitória tipicamente de Pirro.

\section{BIBLIOGRAFIA}

ARIDA, Pérsio. A história do pensamento econômico como teoria e retórica. Mimeo, 1984.

BLANCHARD, O. and FISCHER, S: Lectures on macroeconomics. Cambridge: MIT Press, 1989.

BOURDIEU, Pierre. O campo cientifico. In: ORTIZ, R. (org). Pierre Bourdieu. São Paulo: Editora Ática. Col. Grandes Cientistas Sociais, 1983a. Questões de sociologia. Rio de Janeiro: Marco Zero, 1983b.

DARNTON, Robert. Boemia revolucionária e revolução: $\mathrm{O}$ submundo das letras no antigo regime. São Paulo: Companhia das Letras, 1987

DESCARTES, Rene (1637). Discourse on the method. In: $R$. Descartes: philosophical essays. Indianapolis: Bobbs-Merril Educational Publishing, 1981.

EARL, Peter. A behavioural theory of economists behaviour. In: EICHNER, Alfred (ed). Why economics is not yet a science. London: Macmillan, 1983, p. 90

EICHNER, A. Why economics is not yet a science. Journal of Economic Issues, v. XVII, $n$. 2, June, p. 516, 1983.

GEORGESCU-ROEGEN, N. The interplay between institutional and material factors. In: KREGEL, J. and RONCAGLIA, A. (eds). Barriers to full employment. New York: St. Martin's Press, 1988.

HABERMAS, Jurgen. Conhecimento e interesse. Rio de Janeiro: Editora Guanabara, 1987.

HORKHEIMER, Max. Teoria crítica. Buenos Aires: Amorrortu Editores, 1968.

LAKATOS, Imre. Falsification and the methodology of scientific research programs. In: LAKATOS, I. and MUSGRAVE, A. (eds.). Criticism and the growth of knowledge. Cambridge: Cambridge University Press, 1970.

LIMA Gilberto T. Em busca do tempo perdido: A recuperação pós-keynesiana da economia do emprego de Keynes. Rio de Janeiro: BNDES, 1992.

. Fragments of a transepistemic discourse: political economy of scientific knowledge

and sociology of economic knowledge. São Paulo: FGV/SP. Texto para Discussão Interna, $1994, n^{\circ} 36$.

MANNHEIM, Karl. Ideologia e utopia. Rio de Janeiro: Zahar Editores, 1968

MARX, Karl. Para a critica da economia política. Col. "Os Economistas". São Paulo: Abril Cultural, 1982.

REGO, José Márcio. Retórica e a crítica do método científico em economia: Sociologia do conhecimento versus a lógica da superação positiva. Anais do XVII Encontro Nacional de Economia. Fortaleza: Anpec, 1989.

TOLIPAN, Ricardo. A noção de história do pensamento econômico. In: AMADEO, E.(ed.). Ensaios sobre economia política moderna. São Paulo: Marco Zero, 1989. 
WARD, Benjamin. O que há de errado com a economia? Rio de Janeiro: Zahar Editores, 1975. 